\title{
NON-SYNONIMOUS WNT16 POLYMORPHISMS ALLELES ARE ASSOCIATED WITH DIFFERENT OSTEOARTHRITIS PHENOTYPES
}

Carmen García-Ibarbia, Sara Neila, Carlos Garcés, Maria A. Alonso, María T.

Zarrabeitia, Carmen Valero, Fernando Ortiz and José A. Riancho

Departments of Internal Medicine and Orthopedic Surgery. Hospital UM Valdecilla and University of Cantabria, IDIVAL. Santander. Spain.

\section{Acknowledgements}

Supported by grants from the Instituto de Salud Carlos III (PI 06/0034 and PI 09/0635), which can be co-funded by FEDER Funds from the EU

\section{Correspondence:}

José A. Riancho

Dep. Internal Medicine

Hospital UM Valdecilla

Av Valdecilla sn

39008 Santander

e-mail: rianchoj@unican.es

Tel +34942201990

orcid.org/0000-0003-0691-8755 


\section{INTRODUCTION}

Osteoporosis and osteoarthritis (OA) are the two most common musculoskeletal conditions, both primarily affecting older people, but the relationship between them is still unclear. Whereas reduced bone mineral density (BMD) is a hallmark of osteoporosis (OP), several cross-sectional studies reported that OA is associated with increased BMD (1-4), but other studies found an inverse relation $(5 ; 6)$.

OA was once considered a primary disorder of articular cartilage, but it is now generally thought that bone structure plays a role in the pathologic changes of OA. Typical OA radiographic changes are osteophytes and joint space narrowing (JSN). Sometimes, JSN is the only finding, whereas in other patients this is accompanied by bone formation, revealed in radiographs by large osteophytes and extensive subchondral bone sclerosis in response to cartilage loss. Thus, radiographic OA can be classified as hypertrophic or atrophic, based on the presence or absence of osteophytes (7).

Recently, an increased prevalence of radiographic hip OA and osteophytosis was observed in high BMD cases compared with controls, suggesting that OA in patients with high BMD has a hypertrophic phenotype (8). On the other hand, it has been reported that patients with atrophic hip OA have lower bone volume and thinner trabeculae in iliac crest biopsies (9). In another study, there was a significantly lower prevalence of osteophytes in patients with low phalangeal BMD and knee OA, whereas the prevalence of JSN was higher in the osteopenia and osteoporosis group than in subjects with normal BMD (10). Overall, these results suggest that the relation between $\mathrm{BMD}$ and $\mathrm{OA}$ could vary depending on the $\mathrm{OA}$ phenotype.

The etiology of OP and OA is multifactorial, and both genetic susceptibility and environmental factors (including mechanical forces and traumatic injuries, among others), are involved. Twin studies have shown that the influence of genetic factors accounts for 
about $60 \%$ of disease risk in hip OA, $40 \%$ for knee OA (11), and up to $60 \%$ of the variance of BMD (5). The existence of shared genetic factors in both, OA and OP, has been suggested by some association studies (12). It has been speculated that the Wnt pathway could be the link between bone and joint alterations (13). The activation of the Wnt pathway induces activation of the osteoblasts and degradation of the cartilage matrix (14), which leads to bone formation and cartilage destruction, respectively. In general, the activation of the Wnt pathway is considered to have an anabolic effect on bone (15). However, in the skeletal environment there are 19 different Wnt ligands, which act through various signalling pathways, as well as a number of Wnt inhibitors (16). Thus the effects of Wnt ligands may be rather complex.

Polymorphisms in a number of genes that belong to this pathway have been associated with skeletal traits in several candidate gene and genome-wide studies (17). In particular, WNT16 polymorphisms have been associated with BMD, and a positive effect of WNT16 on bone mass has been shown in several experimental models (18-21). Recently, whole genome sequencing has identified a novel low frequency non coding variant near WNT16 with large effects on BMD (22). I a previous study we reported associations between some genes involved in the Wnt pathway and OA (23), but we did not find statistical evidence for association between OA and polymorphisms in WNT16. However, in that study the OA phenotype was not taken into consideration. Wnt16 appears to be involved in cartilage homeostasis. In fact, Wnt16 expression is increased in damaged cartilage (24) and it may help to support the homeostasis of progenitor cells (25). Hence, in view of the effects of Wnt16 on both bone and cartilage homeostasis, and the emerging interactions between bone and cartilage in the osteoarthritis joints, which are likely different across OA phenotypes, the aim of this study was to test the hypothesis that common allelic variations of WNT16 could influence the OA phenotype. 


\section{PATIENTS AND METHODS}

\section{Subjects}

We analysed the radiographs of 509 Caucasian patients with OA of the large joints of lower limbs (363 with hip OA and 146 with knee OA), aged 46-89 years. They were part of a previous study, which included the collection of DNA samples from patients undergoing prosthetic replacement surgery due to severe hip or knee OA. Patients with secondary OA or with non-Spanish ancestors were excluded (23). The study was performed according to the principles of Helsinki Declaration; participants gave informed consent and the study was approved by the IRB (Comité de Etica en Investigación Clínica de Cantabria)

\section{Assessment of radiographs}

Antero-posterior radiographs of the pelvis were taken with the patient in standing position with $20^{\circ}$ of internal rotation of the lower limbs and radiographs of the knee were taken in standing position too, placing the knee in a semiflexed position and a vertical X-ray beam. Osteoarthritis radiographic changes were graded according to the Atlas of individual radiographic features in osteoarthritis (26). Each joint was classified as hypertrophic or atrophic according to the presence or absence of osteophytes. Osteophyte grade was given by the highest grade. To be classified as atrophic, the joint had to be grade $<2$ for osteophyte and $>2$ for JSN. To be classified as hypertrophic it must be grade $>2$ for osteophyte whatever the JSN was (fig 1). These phenotypic definitions are similar to other reports (27). Two trained observers read the radiographies to reach consensus on the radiographic phenotype, without knowledge of the genotyping results.

\section{Genotyping}

We analyzed two SNPs in WNT16, rs2707466 and rs2908004, which have previously been associated with BMD (19;20;28). DNA was isolated from peripheral blood or buccal swabs by using column-based commercial methods and quantified with the Qubit procedure 
(Invitrogen). The loci were analyzed by a mass-array Sequenom platform at the Centro Nacional de Genotipado (Santiago de Compostela, Spain) or by using Taqman assays (Life Technologies) in our own laboratory in Cantabria University. Duplicate samples were used to confirm the consistency of both procedures.

\section{Statistical analysis}

The association between genotypes and hip or knee OA phenotype was analyzed by logistic regression. The possible confounding effect of other covariates, like age, sex and body mass index (BMI), was explored in multivariate linear regression models.

\section{RESULTS}

The demographic characteristics of the patients are summarized in Table 1. There were no differences in age or sex distribution between the hypertrophic and the atrophic phenotypes, either at the hip or the knee. There was a slight difference in BMI $(p=0.03)$ between patients with atrophic and hypertrophic hip OA, but not between hypertrophic and atrophic knee OA $(\mathrm{p}=0.52)$.

Both SNPs were genotyped with a success rate over 97\%. They are located on chromosome 7, $9.2 \mathrm{~kb}$ apart, and they were in strong linkage disequilibrium $\left(\mathrm{r}^{2}=0.99\right)$. Genotypic frequencies did not depart from Hardy-Weinberg equilibrium.

When both sexes were analyzed together, we did not find a significant relationship between either rs2707466 or rs2908004 genotypes and the type of hip OA ( $p=0.14$ and $p=0.19$, respectively), or knee $\mathrm{OA}(\mathrm{p}=0.41$ and $\mathrm{p}=0.16$, respectively), assuming an additive genetic model. However, when the analysis was restricted to the subgroup of males, there was a significant difference in the genotypic frequencies of rs2707466 between hypertrophic and atrophic hip $\mathrm{OA}(\mathrm{p}=0.003)$, with an overrepresentation of $\mathrm{G}$ alleles in the hypertrophic phenotype (OR 2.08; 95\% confidence interval, CI, 1.28-3.38) (table 2). An association in the 
same direction was observed between these alleles and the type of knee OA, with G alleles being more common in the hypertrophic than in the atrophic knee phenotype $(p=0.008, O R$ 1.96, CI 1,19-3,19). Similar associations were found for the rs2908004 SNP (table 3), although it only reached statistical significance for knee OA $(p=0.017$, OR 0.92; CI 0.860.989). All these associations were maintained in models adjusted by age and BMI.

\section{DISCUSSION}

In this, report we analyzed if the hip and knee OA phenotype is influenced by genetic variants of the Wnt ligand WNT16. To our knowledge, this is the first study attempting to explore the association of genetic variants with the OA phenotype. We selected two SNPs in the coding region of WNT16 gene which have been associated with BMD in previous studies (28). Both SNPs represent missense polymorphisms (rs2707466, Thr>Ile; rs2908004, Arg $>$ Gly).

The Wnt signalling cascades have essential roles in development, growth and homeostasis of joints and bones. WNT16 is produced by osteoblasts and inhibits osteoclastogenesis, both directly and indirectly by increasing expression of osteoprotegerin in osteoblasts (29). The importance of WNT16 in the homeostasis of bone mass was confirmed by a Wnt16 (Wnt16-/-) knockout mouse model. These mice have reduced total body BMD, thinner cortical bones at the femur midshaft and reduced bone strength of both femur and tibia (19).

The role of WNT16 in OA has been less defined. Nevertheless, WNT16 expression is increased in areas of damaged cartilage in OA joints (24). Recently, it has been shown that synovial overexpression of Wnt16 increased the incidence of erosive lesions in the superficial cartilage layer, producing similar lesions than in OA (30). However, the actual role of Wnt16 in joint homeostasis is unclear and may be rather complex. In fact, in a recent study Nalesso (25) showed that Wnt16-deficient mice developed more severe OA after 
destabilisation of the medial meniscus than wild type mice. Somewhat surprisingly, the accelerated OA in Wnt16 knock-out mice was associated with excessive activation of canonical Wnt signalling. In vitro experiments helped to explain this paradox and confirmed the complexity of Wn16 effects: it activated canonical Wnt signalling by itself, but blunted the activated effect of Wnt3a, another Wnt ligand.

In the present study, we found that A allele in rs2707466 was more frequent in males with atrophic hip and knee OA phenotype. The T allele in rs2908004 was more frequent only in atrophic knee OA phenotype. What mechanisms are driving this association between Wnt16 variants and the OA phenotype? Some investigators reported an association of higher BMD with the hypertrophic type of OA (8-10). Thus, a direct BMD-mediated influence (with high BMD associated with hypertrophic OA and low BMD with atrophic OA) seems unlikely, because those alleles associated with atrophic OA have been previously associated with higher BMD (28). Therefore, we could speculate that the association between WNT16 and OA phenotype is not related to BMD, but to joint geometry (28) or other factors involved in OA pathogenesis. However, further studies are needed to elucidate the mechanisms actually involved. Also, it is worth mentioning that we studied end stage OA, whereas bone status may change during the development of OA. Animal models indicate that in early OA there is resorption of subchondral bone, which is followed by an over-exuberant repair process that leads to sclerosis of subchondral bone, as well as new bone formation in the form of osteophytes (31). In humans, subchondral cortical bone in early OA of the knee shows changes of osteoporosis, and it is only later in the disease that cortical sclerosis appears, usually after joint space narrowing has become apparent radiographically (32). As OA progresses, the subchondral cortical bone becomes sclerotic, and osteophytes form at both the medial and lateral margins of the tibio-femoral joint (33). Adding more complexity, although some investigators suggested that thicker bones may limit the ability of subchondral bone to 
cushion and absorb physical forces, thus increasing cartilage strain and degradation, others found that osteoporotic bone may accelerate the development of experimental OA (34). WNT16 alleles may influence joint homeostasis and the development of OA by a variety of other mechanisms besides bone mass. Human and rodent studies suggest that Wnt16 may have a stronger effect on cortical bone than on trabecular bone (35). Thus, the association between WNT16 and OA might involve bone and joint geometry instead of BMD (36;37). In addition, as previously mentioned, Wnt16 appears to have direct effects on cartilage homeostasis, influencing protease activity and cell apoptosis $(30 ; 38 ; 39)$..

This study has some limitations and should be regarded as exploratory. The number of patients was limited, especially regarding those with knee OA, and we only included Caucasian patients. Also, we used routine clinical x-rays for the phenotyping, a method that is less accurate than others, such as MRI. Third, given the strong linkage between both SNPs, we cannot establish with certainty which one is actually driving the association.

In conclusion, we found that two SNPs of the WNT16 gene, previously associated with $\mathrm{BMD}$, are associated with the hip and knee OA phenotype in a sex-dependent manner. Further studies are needed to know if these results are generalizable to other populations and the mechanisms involved at the different joint components. Nevertheless, they provide a first-ever suggestion of the involvement of the Wnt pathway in determining the OA phenotype. Additionally, these results imply that future genetic association studies of OA must take the OA subtype into consideration.

\section{Conflicts of interest}

Authors do not have conflicts of interest relevant to this paper 
TABLE 1 Demographic characteristics. Continuous variables are summarized as the mean \pm SD

\begin{tabular}{|c|c|c|c|c|}
\hline \multirow{2}{*}{} & \multicolumn{2}{|c|}{ HIP OA } & \multicolumn{2}{c|}{ KNEE OA } \\
\cline { 2 - 5 } & HYPERTROPHIC & ATROPHIC & HYPERTROPHIC & ATROPHIC \\
\hline Men, n (\%) & $121(69.9)$ & $52(30.1)$ & $20(38.5)$ & $32(61.5)$ \\
\hline Women, n (\%) & $129(67.9)$ & $61(32.1)$ & $38(40.4)$ & $56(59.4)$ \\
\hline Age, years & $69 \pm 8$ & $71 \pm 8$ & $71 \pm 7$ & $71 \pm 7$ \\
\hline BMI, kg/m & $29.0 \pm 4.5$ & $30.2 \pm 4.6$ & $32.2 \pm 3.9$ & $31.7 \pm 4.9$ \\
\hline
\end{tabular}


TABLE 2 Genotypic frequencies of rs2707466 across OA phenotypes.

\begin{tabular}{|c|c|c|c|c|c|c|c|}
\hline \multicolumn{2}{|c|}{ rs2707466 } & \multicolumn{2}{|c|}{ HYPERTROPHIC } & \multicolumn{3}{c|}{ ATROPHIC } \\
\cline { 2 - 8 } & GG & AG & AA & GG & AG & AA \\
\hline \multirow{3}{*}{$\begin{array}{c}\text { HIP } \\
\text { n (\%) }\end{array}$} & All & $88(35.6)$ & $116(47)$ & $43(17.4)$ & $36(32.7)$ & $46(41.7)$ & $28(25.5)$ \\
\cline { 2 - 8 } & Men & $43(36.4)$ & $57(48.3)$ & $18(15.3)$ & $11(21.2)$ & $24(46.2)$ & $17(32.7)$ \\
\cline { 2 - 8 } & Women & $45(34.9)$ & $59(45.7)$ & $25(19.4)$ & $2543.1)$ & $22(37.9)$ & $11(19)$ \\
\hline \multirow{2}{*}{$\begin{array}{c}\text { KNEE } \\
\text { n (\%) }\end{array}$} & All & $23(40.4)$ & $18(31.6)$ & $16(28.1)$ & $22(32.2)$ & $45(51.7)$ & $14(16.1)$ \\
\cline { 2 - 8 } & Men & $9(47.4)$ & $4(21.4)$ & $6(31.6)$ & $4(12.9)$ & $22(71)$ & $5(16.1)$ \\
\cline { 2 - 8 } & Women & $14(36.8)$ & $14(36.8)$ & $10(26.3)$ & $24(42.9)$ & $23(41.1)$ & $9(16.1)$ \\
\hline
\end{tabular}


TABLE 3 Genotypic frequencies of rs2908004 across OA phenotypes.

\begin{tabular}{|c|c|c|c|c|c|c|c|}
\hline \multicolumn{2}{|c|}{ rs2908004 } & \multicolumn{3}{|c|}{ HYPERTROPHIC } & \multicolumn{3}{c|}{ ATROPHIC } \\
\cline { 2 - 8 } & CC & CT & TT & CC & TC & TT \\
\hline \multirow{3}{*}{$\begin{array}{c}\text { HIP } \\
\text { n }(\%)\end{array}$} & All & $87(34.8)$ & $120(48)$ & $43(17.2)$ & $36(30,5)$ & $55(46,6)$ & $27(22.9)$ \\
\cline { 2 - 8 } & Men & $43(35.5)$ & $60(49,6)$ & $18(14.9)$ & $11(21.6)$ & $24(47.1)$ & $16(31.4)$ \\
\cline { 2 - 8 } & Women & $44(34.1)$ & $60(46.5)$ & $25(19.4)$ & $25(41)$ & $25(41.0)$ & $11(18.0)$ \\
\hline \multirow{3}{*}{$\begin{array}{c}\text { KNEE } \\
\text { n (\%) }\end{array}$} & All & $22(40.0)$ & $18(32.7)$ & $15(27.3)$ & $28(32.5)$ & $44(51.2)$ & $14(16.3)$ \\
\cline { 2 - 8 } & Men & $9(47.4)$ & $4(21.1)$ & $6(31.6)$ & $4(13.3)$ & $21(70.0)$ & $5(16.7)$ \\
\cline { 2 - 8 } & Women & $13(36.1)$ & $14(38.9)$ & $9(25.0)$ & $24(42.9)$ & $23(41.1)$ & $9(16.1)$ \\
\hline
\end{tabular}




\section{FIGURE LEGENDS}

Figure 1. Typical x-rays of patients with atrophic (left) and hypertrophic (right) OA. Arrows point to osteophytes.

Figure 2. Frequency of hip OA phenotypes across rs2707466 genotypes in males. 


\section{Reference List}

(1) Foss MV, Byers PD. Bone density, osteoarthrosis of the hip, and fracture of the upper end of the femur. Ann Rheum Dis 1972; 31(4):259-264.

(2) Burger H, Van Daele PL, Odding E, Valkenburg HA, Hofman A, Grobbee DE et al. Association of radiographically evident osteoarthritis with higher bone mineral density and increased bone loss with age. The Rotterdam Study. Arthritis Rheum 1996; 39(1):81-86.

(3) Hannan MT, Anderson JJ, Zhang Y, Levy D, Felson DT. Bone mineral density and knee osteoarthritis in elderly men and women. The Framingham Study. Arthritis Rheum 1993; 36(12):1671-1680.

(4) Hart DJ, Mootoosamy I, Doyle DV, Spector TD. The relationship between osteoarthritis and osteoporosis in the general population: the Chingford Study. Ann Rheum Dis 1994; 53(3):158-162.

(5) Lingard EA, Mitchell SY, Francis RM, Rawlings D, Peaston R, Birrell FN et al. The prevalence of osteoporosis in patients with severe hip and knee osteoarthritis awaiting joint arthroplasty. Age Ageing 2010; 39(2):234-239.

(6) Akamatsu Y, Mitsugi N, Taki N, Takeuchi R, Saito T. Relationship between low bone mineral density and varus deformity in postmenopausal women with knee osteoarthritis. J Rheumatol 2009; 36(3):592-597.

(7) Solomon L. Patterns of osteoarthritis of the hip. J Bone Joint Surg Br 1976; 58(2):176-183.

(8) Hardcastle SA, Dieppe P, Gregson CL, Hunter D, Thomas GE, Arden NK et al. Prevalence of radiographic hip osteoarthritis is increased in high bone mass. Osteoarthritis Cartilage 2014; 22(8):1120-1128.

(9) Schnitzler CM, Mesquita JM, Wane L. Bone histomorphometry of the iliac crest, and spinal fracture prevalence in atrophic and hypertrophic osteoarthritis of the hip. Osteoporos Int 1992; 2(4):186-194.

(10) Deng ZH, Zeng C, Li YS, Yang T, Li H, Wei J et al. Relation between phalangeal bone mineral density and radiographic knee osteoarthritis: a cross-sectional study. BMC Musculoskelet Disord 2016; 17(1):71.

(11) Spector TD, MacGregor AJ. Risk factors for osteoarthritis: genetics. Osteoarthritis Cartilage 2004; 12 Suppl A:S39-S44.

(12) Yerges-Armstrong LM, Yau MS, Liu Y, Krishnan S, Renner JB, Eaton CB et al. Association analysis of BMD-associated SNPs with knee osteoarthritis. J Bone Miner Res 2014; 29(6):1373-1379. 
(13) Sharma AR, Jagga S, Lee SS, Nam JS. Interplay between cartilage and subchondral bone contributing to pathogenesis of osteoarthritis. Int J Mol Sci 2013; 14(10):1980519830.

(14) Corr M. Wnt-beta-catenin signaling in the pathogenesis of osteoarthritis. Nat Clin Pract Rheumatol 2008; 4(10):550-556.

(15) Krishnan V, Bryant HU, Macdougald OA. Regulation of bone mass by Wnt signaling. J Clin Invest 2006; 116(5):1202-1209.

(16) Glass DA, Karsenty G. Molecular bases of the regulation of bone remodeling by the canonical Wnt signaling pathway. Curr Top Dev Biol 2006; 73:43-84.

(17) Estrada K, Styrkarsdottir U, Evangelou E, Hsu YH, Duncan EL, Ntzani EE et al. Genome-wide meta-analysis identifies 56 bone mineral density loci and reveals 14 loci associated with risk of fracture. Nat Genet 2012; 44(5):491-501.

(18) Rivadeneira F, Styrkarsdottir U, Estrada K, Halldorsson BV, Hsu YH, Richards JB et al. Twenty bone-mineral-density loci identified by large-scale meta-analysis of genome-wide association studies. Nat Genet 2009; 41(11):1199-1206.

(19) Zheng HF, Tobias JH, Duncan E, Evans DM, Eriksson J, Paternoster L et al. WNT16 influences bone mineral density, cortical bone thickness, bone strength, and osteoporotic fracture risk. PLoS Genet 2012; 8(7):e1002745.

(20) Koller DL, Zheng HF, Karasik D, Yerges-Armstrong L, Liu CT, McGuigan F et al. Meta-analysis of genome-wide studies identifies WNT16 and ESR1 SNPs associated with bone mineral density in premenopausal women. J Bone Miner Res 2013; 28(3):547-558.

(21) Styrkarsdottir U, Halldorsson BV, Gretarsdottir S, Gudbjartsson DF, Walters GB, Ingvarsson $\mathrm{T}$ et al. New sequence variants associated with bone mineral density. Nat Genet 2009; 41(1):15-17.

(22) Zheng HF, Forgetta V, Hsu YH, Estrada K, Rosello-Diez A, Leo PJ et al. Wholegenome sequencing identifies EN1 as a determinant of bone density and fracture. Nature 2015; 526(7571):112-117.

(23) Garcia-Ibarbia C, Perez-Castrillon JL, Ortiz F, Velasco J, Zarrabeitia MT, Sumillera $\mathrm{M}$ et al. Wnt-related genes and large-joint osteoarthritis: association study and replication. Rheumatol Int 2013; 33(11):2875-80.

(24) Dell'Accio F, De Bari C, Eltawil NM, Vanhummelen P, Pitzalis C. Identification of the molecular response of articular cartilage to injury, by microarray screening: Wnt16 expression and signaling after injury and in osteoarthritis. Arthritis Rheum 2008; 58(5):1410-1421.

(25) Nalesso G, Thomas BL, Sherwood JC, Yu J, Addimanda O, Eldridge SE et al. WNT16 antagonises excessive canonical WNT activation and protects cartilage in osteoarthritis. Ann Rheum Dis 2017;76(1):218-226. 
(26) Altman RD, Gold GE. Atlas of individual radiographic features in osteoarthritis, revised. Osteoarthritis Cartilage 2007; 15 Suppl A:A1-56.

(27) Nevitt MC, Lane NE, Scott JC, Hochberg MC, Pressman AR, Genant HK et al. Radiographic osteoarthritis of the hip and bone mineral density. The Study of Osteoporotic Fractures Research Group. Arthritis Rheum 1995; 38(7):907-916.

(28) Garcia-Ibarbia C, Perez-Nunez MI, Olmos JM, Valero C, Perez-Aguilar MD, Hernandez JL et al. Missense polymorphisms of the WNT16 gene are associated with bone mass, hip geometry and fractures. Osteoporos Int 2013; 24(9):2449-54.

(29) Moverare-Skrtic S, Henning P, Liu X, Nagano K, Saito H, Borjesson AE et al. Osteoblast-derived WNT16 represses osteoclastogenesis and prevents cortical bone fragility fractures. Nat Med 2014; 20(11):1279-1288.

(30) van den Bosch MH, Blom AB, Sloetjes AW, Koenders MI, Van de Loo FA, Van den Berg WB et al. Induction of Canonical Wnt Signaling by Synovial Overexpression of Selected Wnts Leads to Protease Activity and Early Osteoarthritis-Like Cartilage Damage. Am J Pathol 2015; 185(7):1970-1980.

(31) Hayami T, Pickarski M, Wesolowski GA, McLane J, Bone A, Destefano J et al. The role of subchondral bone remodeling in osteoarthritis: reduction of cartilage degeneration and prevention of osteophyte formation by alendronate in the rat anterior cruciate ligament transection model. Arthritis Rheum 2004; 50(4):1193-1206.

(32) Buckland-Wright C. Subchondral bone changes in hand and knee osteoarthritis detected by radiography. Osteoarthritis Cartilage 2004; 12 Suppl A:S10-S19.

(33) Felson DT, Neogi T. Osteoarthritis: is it a disease of cartilage or of bone? Arthritis Rheum 2004; 50(2):341-344.

(34) Bellido M, Lugo L, Roman-Blas JA, Castaneda S, Calvo E, Largo R et al. Improving subchondral bone integrity reduces progression of cartilage damage in experimental osteoarthritis preceded by osteoporosis. Osteoarthritis Cartilage 2011; 19(10):12281236.

(35) Gori F, Lerner U, Ohlsson C, Baron R. A new WNT on the bone: WNT16, cortical bone thickness, porosity and fractures. Bonekey Rep 2015; 4:669.

(36) Doherty M, Courtney P, Doherty S, Jenkins W, Maciewicz RA, Muir K et al. Nonspherical femoral head shape (pistol grip deformity), neck shaft angle, and risk of hip osteoarthritis: a case-control study. Arthritis Rheum 2008; 58(10):3172-3182.

(37) Lynch JA, Parimi N, Chaganti RK, Nevitt MC, Lane NE. The association of proximal femoral shape and incident radiographic hip OA in elderly women. Osteoarthritis Cartilage 2009; 17(10):1313-1318.

(38) Zhu M, Tang D, Wu Q, Hao S, Chen M, Xie C et al. Activation of beta-catenin signaling in articular chondrocytes leads to osteoarthritis-like phenotype in adult betacatenin conditional activation mice. J Bone Miner Res 2009; 24(1):12-21. 
(39) Lories RJ, Peeters J, Bakker A. Articular cartilage and biomechanical properties of the long bones en Frzb-knockout mice. Arthritis Rheum 2007; 56: 4095-4103. 


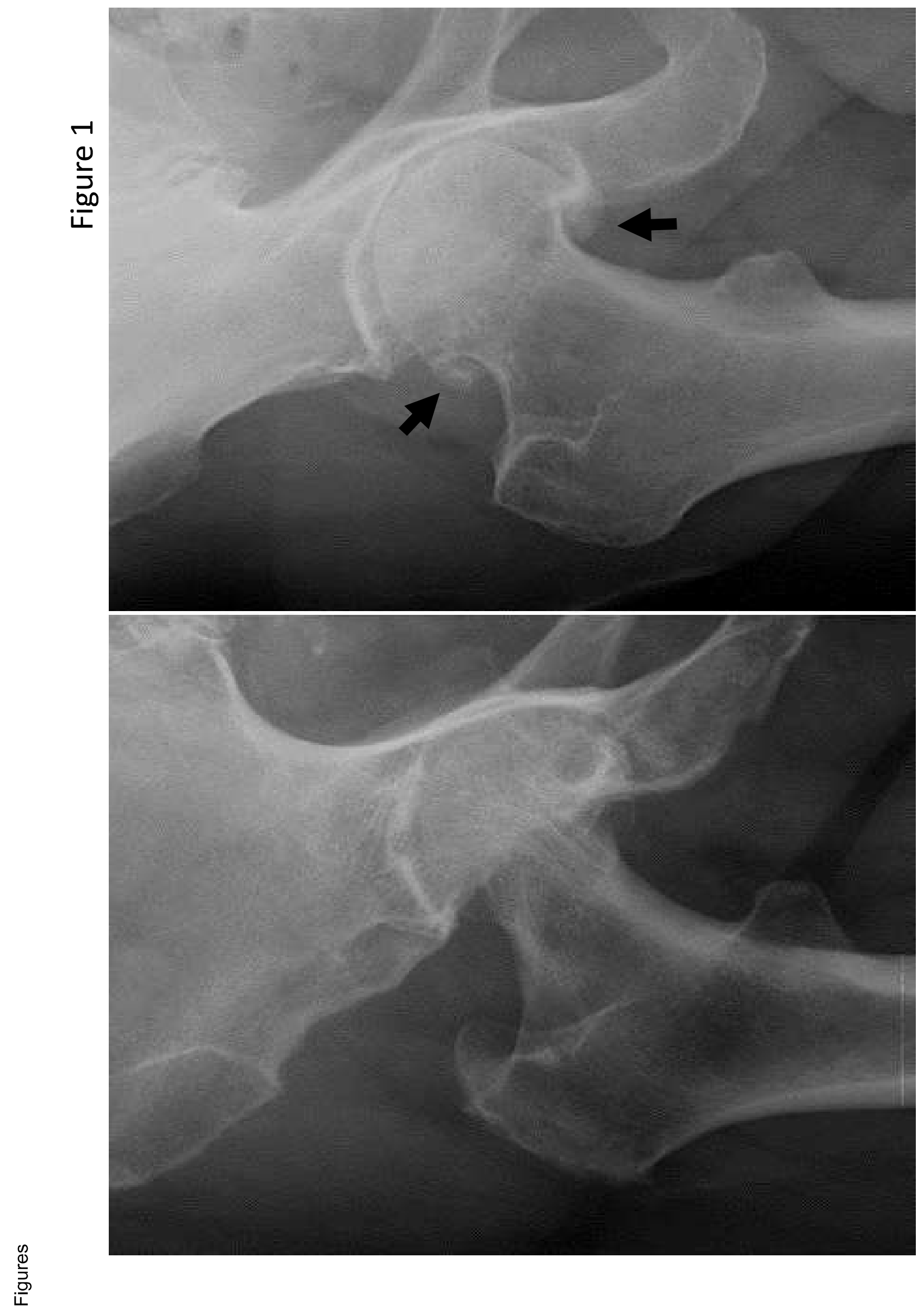


N

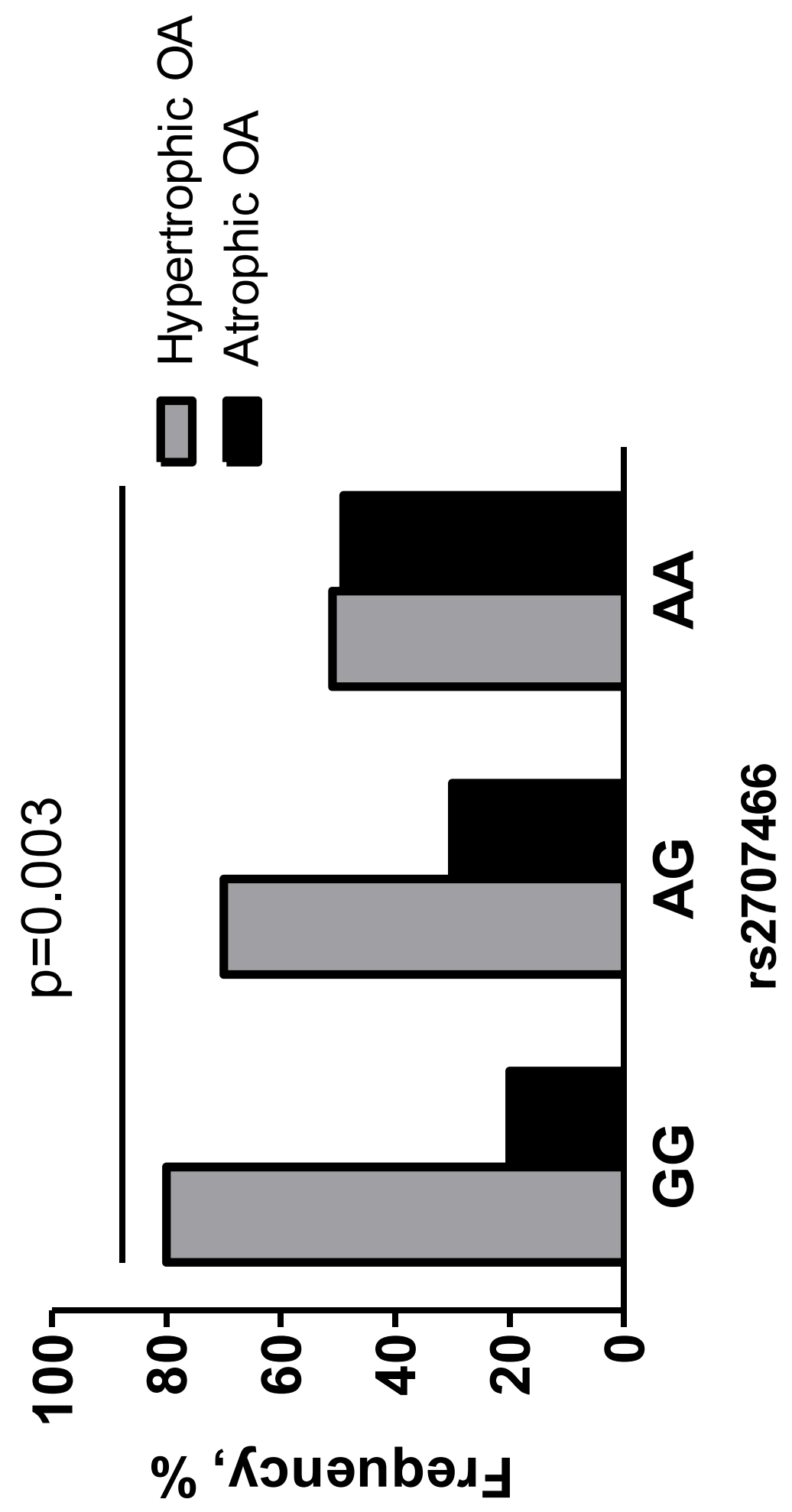

